\title{
The effect of location on the discrimination of spatial vibrotactile patterns
}

\author{
DAVID T. HORNER \\ University of Wisconsin, Oshkosh, Wisconsin
}

\begin{abstract}
The present study examined whether the locations of patterns on the skin affected the ability to process information about their shapes. In Experiment 1, pairs of spatial vibrotactile patterns, using the array from the Optacon, were presented sequentially to subjects' left index fingerpads. The location of each pattern in a pair was varied randomly among four locations on the skin. The subjects responded "same" or "different" on the basis of the shapes of patterns, regardless of their locations. Discrimination accuracy was highest and response time fastest when patterns occupied identical locations (ILs), and performance suffered with increasing distance between patterns. In Experiment 2, pairs were presented to corresponding points or to noncorresponding points on separate fingerpads. When patterns occupied corresponding points on separate fingers, accuracy was lower than when patterns occupied ILs on a single finger, but higher than when patterns occupied noncorresponding points on separate fingers. The results suggested that discriminability declined partly because patterns did not occupy ILs, and partly because separate locations had different densities of innervation.
\end{abstract}

To what extent is information about the shape of a tactile spatial pattern independent of the location on the skin to which it is presented? The importance of location probably depends on the nature of the task performed by the skin. One can imagine situations in which location is important for shape perception, as well as those in which it might be irrelevant. For example, when feeling a braille character on an elevator console, it may not be important to know the character's location on the fingerpad; location may, however, be important when trying to find a symbol on a tactual map, such as a raised square indicating a particular building. In such a case, if the fingerpad is following a horizontal raised line indicating a street, a square above the line may be perceived as being different from a square below the line.

In the present study, the locations of patterns were varied on the skin, but location was defined by the experimenter as an irrelevant attribute; the subjects were asked to ignore location and to process only the shapes of patterns. The question was whether the subjects would, in fact, be able to process shapes of patterns independent of their locations on the skin. As used here, the term "independent" refers to whether or not changing the locations of patterns, while keeping their shapes constant, alters their discriminability.

This research was supported by Northeast Missouri State University, by the University of Wisconsin Oshkosh, and by Grant DC-00095 from the National Institutes of Health. I wish to thank James Craig for his comments on this manuscript and Roger Rhodes for assistance in conducting these experiments. My thanks also go to Lester Krueger, Janet Weisenberger, Mark Hollins, and an anonymous reviewer for helpful comments on an earlier version of this paper. Address correspondence to D. T. Horner, Department of Psychology, University of Wisconsin Oshkosh, Oshkosh, WI 54901 (e-mail: horner@vaxa.cis.uwosh.edu).
In studies of vibrotactile-pattern perception using relatively dense arrays of vibrators, spatial patterns have usually been presented only to a single location on the skin. Studies examining the perception of patterns presented to more than one location have focused on the processing capabilities of different body sites (Cholewiak \& Craig, 1984; Craig, 1977; Loomis, 1980). Scadden (1973) used the same patterns and the same observers to measure letter recognition on the abdomen, thigh, and back using the tactile vision substitution system (Scadden, 1969; White, Saunders, Scadden, Bach-y-Rita, \& Collins, 1970). Recognition accuracy was best on the abdomen, even though the observers had been highly trained in pattern recognition on the back prior to testing. Scadden concluded that the immediate transfer of learning from a practiced site to a novel site was based on higher-order, centrally controlled processes rather than on a reorganization of neural networks that would have required extensive relearning. In the present study, a very different method was used to measure the effect of location on the ability to process information about the shapes of spatial vibrotactile patterns presented to the fingerpad.

A preliminary observation suggested that location may be important for the perception of tactile spatial patterns. Specifically, pairs of letter-shaped vibrotactile patterns were presented sequentially to the fingerpad either at identical locations (ILs) or at nonidentical locations (NILs). The subjects were asked to identify the first pattern in each pair and to ignore the second pattern. As expected, when pairs of different letters were presented, there was more interference (masking) when letters were at ILs than there was when they were at NILs (Loomis \& Apkarian-Stielau, 1976; Weisenberger, 1981). However, when pairs of same letters were presented, the reverse was true - that is, there was more interference when let- 
ters were at NILs than there was when they were at ILs. In short, the same letter presented to a different location interfered as if it were a different letter. Such a result suggests that location may be an important feature of tactile spatial patterns.

Neuroanatomical evidence from nonhuman primates indicates that location is preserved at a cortical level and that the somatosensory cortex contains multiple representations of peripheral inputs from the skin (Allard \& Merzenich, 1988; Kaas, Merzenich, \& Killackey, 1984; Merzenich et al., 1983; Merzenich et al., 1984). The relationship that exists between the cortical distance between initial representations of patterns and the physical or perceptual distance between patterns at different skin locations is unclear (Evans, Craig, \& Rinker, 1992). However, cortical representations are organized somatotopically, and location thus appears to be preserved at least at an initial level of processing, in which separate sets of cortical cells are activated in response to stimuli at different locations.

There are also multiple cortical representations of the visual field (for a review, see Maunsell \& Newsome, 1987), and it has been suggested that there are separate cortical pathways for processing location and shape information visually (Mishkin, Ungerleider, \& Macko, 1983; Ungerleider \& Mishkin, 1982). Consistent with this notion, studies of visual attention have shown that subjects may correctly name which letters were presented while incorrectly reporting the locations of the letters (Estes, Allmeyer, \& Reder, 1976; Mozer, 1989; Treisman \& Gelade, 1980). However, the distance between stimulus locations has not been varied systematically to observe its effect on shape-processing capabilities in tactile studies of pattern perception on a single fingerpad.

The role of location is studied not only in connection with theoretical issues of pattern processing; a practical reason for examining it concerns the improvement of tactile communication systems that rely on our ability to process successive spatial patterns, such as braille (Nolan \& Kederis, 1969), the Optacon (Bliss, Katcher, Rogers, \& Shepard, 1970), and Tadoma, a tactile method of speech comprehension used by some deaf-blind individuals (Reed, Durlach, Braida, \& Schultz, 1982). For example, Optacon patterns are presented to a single fingerpad, and the location at which the patterns are felt may affect reading performance. Performance may also be affected by temporal masking (Craig, 1976, 1978, 1982a, 1982b, 1983a; Craig \& Evans, 1987; Evans, 1987; Evans \& Craig, 1986) and by spatial interactions between successive patterns presented to the skin (Craig, 1980, 1989; Evans, 1987; Evans \& Craig, 1986; Loomis \& Apkarian-Stielau, 1976; Weisenberger \& Craig, 1982). Temporal masking and spatial interactions between patterns may be reduced as the physical distance between patterns on the skin increases, resulting in improved legibility. Measuring the effect of location on perception should provide information concerning the extent of temporal and spatial interactions as physical distance between patterns increases.
In the present study, a discrimination task was used to examine the role of location in perceiving spatial patterns. On each trial, two patterns were presented sequentially either to ILs or to NILs. The subjects were asked to judge whether the shapes of the patterns were the same or different, independent of where the patterns were presented. A discrimination task was chosen for several reasons: First, discrimination is often considered to be a more basic measure of the ability to process patterns than is identification, partly because identification requires learning pattern names and retaining them in memory (Posner \& Mitchell, 1967; Proctor, 1981; Robinson, Brown, \& Hayes, 1964); second, discrimination directly addresses the primary question of interest-namely, how does varying pattern location affect the ability to process shapes? Discrimination performance when patterns occupied ILs was directly compared with performance when the locations of patterns were varied; and finally, discrimination requires the processing not of a single pattern, but of pairs of patterns, a task that is more representative of the usual way spatial patterns are processed by the skin (patterns arrive on the fingerpad in a temporal sequence as the fingers move over the surface of an object).

\section{EXPERIMENT 1}

To the extent that perceived shape is independent of the absolute location of patterns on the skin, discrimination performance may not change as location is varied. However, if location is an important feature for processing pattern shapes, performance might be expected to vary with changes in location. For example, if temporal or spatial masking is reduced with an increase in the distance between locations, discrimination performance might improve when patterns occupy separate locations. On the contrary, if location is a featural property of patterns, performance may decline as patterns occupy increasingly separate locations.

Previous studies of vibrotactile-pattern discrimination have varied the time between pattern onsets- the stimulus onset asynchrony (SOA) - in order to examine temporal characteristics of pattern processing (Cholewiak \& Craig, 1984; Craig, 1983a, 1985a; Horner, 1991, 1992; Horner \& Craig, 1989). In Experiment 1, it was varied for several reasons: (1) the subjects would feel only a single stimulus if patterns simultaneously occupied ILs; (2) spatial patterns are usually felt sequentially as the fingerpad moves across a surface, and hence the time between successive patterns varies; and (3) varying the SOA manipulated the rate at which information was presented to the skin, thereby determining the extent to which varying location affected the rate at which information was processed.

\section{Method}

Subjects. Six subjects were tested, all of whom had received practice in identifying letterlike patterns. Of the subjects, three female and two male undergraduates were paid for their participation; the sixth subject was the author 
Apparatus. A PDP-1 1/34 computer was used to control the amplitude and duration of vibration of the individual pins in the vibratory array of the Optacon, a reading aid for the blind (Bliss et al., 1970). The vibratory array measured $11.45 \times 27.14 \mathrm{~mm}$ (width $x$ height) and consisted of 144 blunt pins arranged in 24 rows (with the rows separated by $1.18 \mathrm{~mm}$ ) and 6 columns (each separated by $2.3 \mathrm{~mm}$ ). Each of the $.25-\mathrm{mm}$ diam pins vibrated at $230 \mathrm{~Hz}$, and at $33 \mathrm{~V}$ to the driver circuits, a comfortable intensity that was we!! above threshold, resulting in a maximum skin indentation of $65 \mu \mathrm{m}$ (Bliss et al., 1970, Bliss \& Linvill, 1966). The vibratory array contacted the distal portion of the left index fingerpad.

Stimuli. The stimuli were patterns shaped like a letter " $T$ " and a letter "L" (see Figure 1). Each pattern was presented for $26 \mathrm{msec}$ in a static mode, in which all of the pins in the pattern were activated simultancously (Craig, 1980). As shown in Figure 1, each pattern occupied an area on the array that measured 6 columns wide $\times 9$ rows deep (i.e., $11.45 \times 9.44 \mathrm{~mm}$ ). In addition, the patterns were activated randomly at one of the following four locations on the array: Rows 1-9 (Location 1); Rows 4-12 (Location 2); Rows 7-15 (Location 3); or Rows 10-18 (Location 4). On any given trial, any of the following presentations was possible: a pair of patterns could occupy ILs; the centers of the patterns could be separated by
3 rows $(3.54 \mathrm{~mm})$; the centers could be separated by 6 rows $(7.08 \mathrm{~mm})$; or they could be separated by 9 rows $(10.62 \mathrm{~mm})$. Pins in Rows 19-24 remained inactive. The area covered by all four locations combined was $11.45 \times 20.06 \mathrm{~mm}$ (width $\times$ height).

Procedure. The subjects were shown visual representations of the patterns in Figure l at each of the four locations before the experiment began. They were told that on each trial, a pair of patterns would be presented sequentially, and that each of the patterns would be presented randomly at one of the four locations. They were further told to ignore the location at which the patterns were felt on the fingerpad, and to decide whether the patterns were the same or different on the basis of their shape. The subjects were seated with their left index finger on the tactile array in front of them. All used their right hand to initiate trials, by pressing the space bar on a computer keyboard, and they responded by pressing either the " $\mathrm{S}$ " key on the keyboard for a "same" response or the "D" key for a "different" response. To eliminate auditory information from the array, the subjects wore earplugs and earphones emitting low-pass, filtered noise.

On each trial, the subjects received a cue stimulus consisting of the first and last pins in the top two rows, simultaneously activated for $13 \mathrm{msec}$. The cue stimulus also served as a way of ensuring that a) LOCATION 1

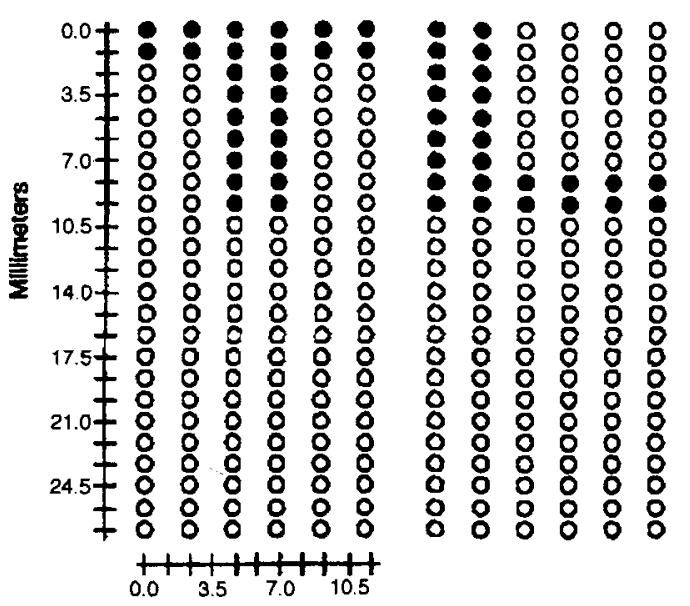

\section{b) LOCATION 2}

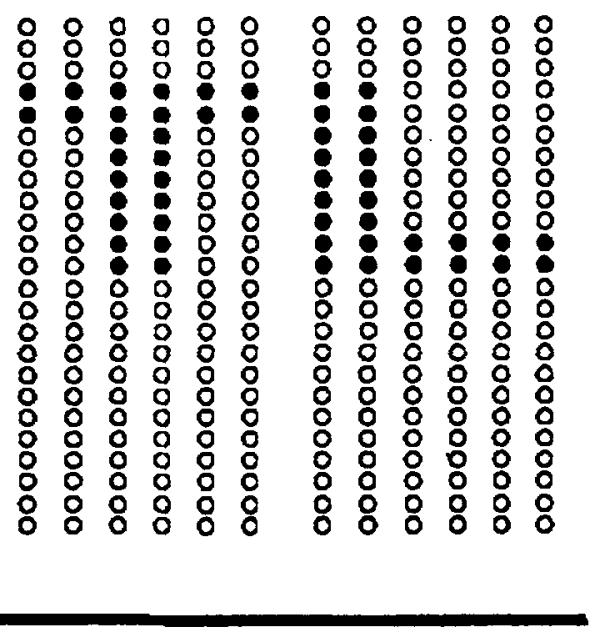

\section{d) LOCATION 4}
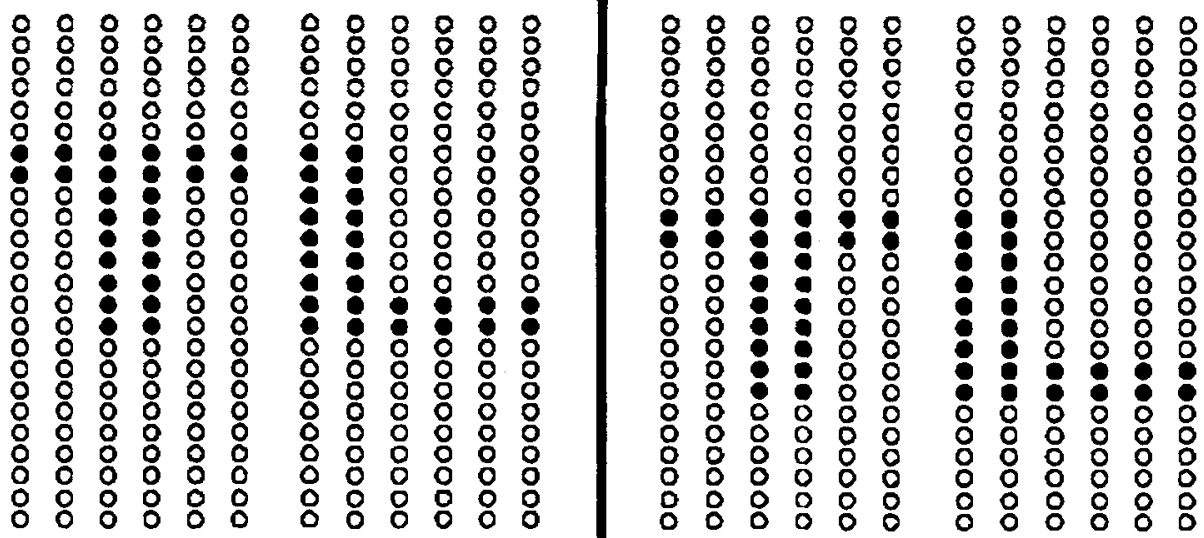

Figure 1. Representations of the " $T$ " and " $L$ " patterns at each of the four array locations (a-d) at which the patterns were presented. Filled circles indicate activated pins in the array, and unfilled circles indicate inactive pins. Spacings between pins are drawn to scale, but the circles indicating pins are not to scale. 
the finger was correctly positioned on the array. One sec after the cue stimulus, the first pattern was presented randomly to one of the four locations, followed by the second pattern, also presented randomly and independently, to one of the four locations. Thus, although trials were not blocked by the locations of patterns, overall, $25 \%$ of the trials were ILs and $75 \%$ were NILs. These percentages also represented the probabilities of any particular trial consisting of ILs or NILs. The SOA was varied using values of 100,300 , and $1,000 \mathrm{msec}$.

After the pair of patterns were presented, the subjects judged whether the shapes of the patterns were the same or different (by giving a "same" response or a "different" response, respectively), regardless of which locations the patterns occupied. They were told that on half of the trials a pair of same-shaped patterns would be presented (a same trial), and that on the other half a pair of different-shaped patterns would be presented (a different trial). Trial-bytrial feedback was provided, consisting of either the word "correct" or, when the response was incorrect, an " $S$ " or a " $D$ " (corresponding to whichever the correct choice was) appearing on a visual display in front of the subject. The subjects were also told to respond as quickly as possible, without sacrificing accuracy for speed. Accuracy was therefore emphasized, and no response-time feedback was provided.

Within an experimental session, same and different trials were presented randomly in 60 -trial blocks, each block testing a different SOA. Each session contained six blocks (two blocks per SOA condition), with the order of blocks determined randomly, for a total of 360 trials per session, half of which were same and the other half different. The first three of seven sessions were practice sessions; the data analyses focused on the last four sessions $(480$ trials per SOA condition for each subject) because the experimental questions were most relevant to asymptotic performance, and there was little change in performance after the third session. Trials with RTs of below $100 \mathrm{msec}$ or above $1.5 \mathrm{sec}$ were excluded from the analyses.

\section{Results}

The percentage of correct discrimination responses and the mean response time (RT) on correct trials were analyzed according to the locations of the two patterns on each trial. The subjects showed a distinct tendency to respond "same." Averaged across subjects, the rate of "same" responses ranged from $62 \%$ to $72 \%$ as a function of SOA when patterns were presented to ILs. Therefore, the accuracy data were used to calculate $P(C)$ max at each SOA. $P(C)$ max is the area of the standard normal distribution corresponding to a $z$-score of $d^{\prime} / 2$, and is the proportion correct had subjects adopted a symmetric criterion of $[p$ ("same") $=p$ ("different") $=0.5]$; this statistic (McFadden, 1970) minimizes the effects of such response tendencies, and has been used in previous discrimination studies that have found similar response tendencies when patterns were presented to a single location (Craig, 1983a; Horner, 1991; Horner \& Craig, 1989). Specifically, the data were scored in terms of hits (responding "different" on a different trial) and false alarms (responding "different" on a same trial). Hits and false alarms were used to calculate $d^{\prime}$ and $\mathrm{P}(\mathrm{C})$ max.

To measure the effect of location on the ability to discriminate the shapes of patterns, performance when pairs of patterns were at ILs was analyzed separately from that when pairs were at NILs. IL performance as a function of SOA was analyzed separately for each of the four lo- cations that the pairs of patterns occupied, and there were no significant differences among the four locations in terms of either $\mathrm{P}(\mathrm{C}) \max [F(3,15)=2.28, p>.05]$ or RT $[F(3,15)=0.55, p>.05]$. The IL data were therefore averaged, and $\mathrm{P}(\mathrm{C})$ max and RT are shown as functions of SOA in Figure 2. Each IL data point represents at least 718 trials from six subjects. The NIL data were analyzed on the basis of the distance between patterns on each trial. Figure 2 shows $\mathrm{P}(\mathrm{C})$ max and RT as a function of SOA when patterns were presented to locations separated by $3.54,7.08$, or $10.62 \mathrm{~mm}$. Each NIL data point represents at least 366 trials from six subjects. The standard errors of the means ranged from $4 \%$ to $6 \%$ for $P(C)$ max, and from 27 to $54 \mathrm{msec}$ for RT, and did not differ systematically across locations or SOAs. The data for individual subjects were similar to those in Figure 2.

Accuracy declined as the distance between pattern locations was increased, showing that location plays an important role when the shapes of patterns presented to a single fingerpad are being distinguished. A two-way repeated measures analysis of variance (ANOVA) on the $\mathrm{P}(\mathrm{C})$ max data revealed an effect of location [ILs vs. NILs separated by either $3.54,7.08$, or $10.62 \mathrm{~mm} ; F(3,15)=$ $19.60, p<.001]$ and an effect of SOA $[F(2,10)=53.36$, $p<.001]$, but no interaction between location and SOA $[F(6,30)=0.54, p>.05]$. The effect of SOA reflects the general improvement in performance as the time between patterns was increased, a result that has been found in previous studies of discrimination, and that may be due to reduced temporal masking (Cholewiak \& Craig, 1984; Craig, 1983a; Horner, 1991; Horner \& Craig, 1989). The

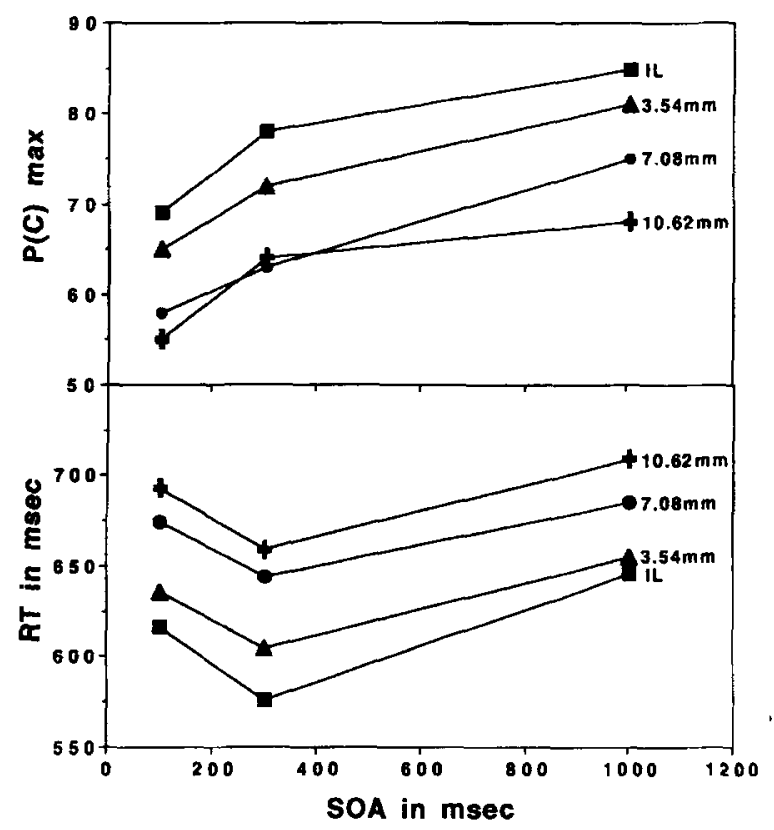

Figure 2. Discrimination accuracy $[P(C)$ max] and response time (RT) plotted as a function of $\mathrm{SOA}$ when patterns were presented either to ILs or to NILs, the latter separated by either $3.54,7.08$, or $10.62 \mathrm{~mm}$. 
lack of an interaction between location and SOA shows that the effect of location on discrimination performance is independent of the time between patterns.

The results of a similar ANOVA on the RT data revealed an effect of location $[F(3,15)=27.29, p<.001]$, which reflects the increase in RT with increasing distance between pattern locations. However, there was no effect of SOA $[F(2,10)=3.28, p>.05]$, nor was there any interaction between location and SOA $[F(6,30)=$ $0.21, p>.05]$. Despite the fact that accuracy improved as the SOA was increased, there was no significant decrease in RT with increasing SOA. Paired $t$ tests between successive RT means on the IL function - the function showing the greatest change in RT with SOA-did reach significance [100 msec vs. $300 \mathrm{msec}: t(5)=2.93, p<.04$; 300 msec vs. $1,000 \mathrm{msec}: t(5)=-3.17, p<.03]$. Thus, when the SOA was increased from $100 \mathrm{msec}$ to $300 \mathrm{msec}$, RT became faster and accuracy improved, as would be expected with a concurrent reduction in masking. Faster RT at the 300-msec SOA might also be expected if the first stimulus provided a cue that the subjects could use to prepare for the arrival of the second stimulus. Such a cue might be less useful at the briefest SOA. Slower RT at the $1,000-\mathrm{msec}$ SOA compared with that at the $300-$ msec SOA might be due to increased uncertainty about the time of arrival of the second stimulus. However, as was true for the accuracy data, there was no interaction between location and SOA, showing that the differences in RT for the IL and NIL data were consistent across SOAs.

\section{Discussion}

The fact that accuracy was higher and RT was faster when patterns were presented to ILs than when they were presented to NILs argues against a speed-accuracy tradeoff, and indicates an advantage in both speed and accuracy when processing patterns at ILs. Although temporal masking may account for changes in performance with varying SOA, it does not explain the reduction in accuracy with increasing distance between patterns. In fact, increasing the distance between patterns should have reduced masking (Loomis \& Apkarian-Stielau, 1976; Weisenberger, 1981). Examining the frequency of "same" and "different" responses as a function of distance may help to account for the reduction in accuracy with increasing distance between patterns. As reported above, the subjects had a tendency to respond "same" when patterns were presented to ILs. Figure 3 shows the percentage of "same" responses averaged across subjects as a function of SOA for ILs and for NILs. The standard errors of the means ranged from $4 \%$ to $6 \%$, and did not differ systematically across either locations or SOAs.

The frequency of "same" responses declined as the distance between patterns was increased-or, stated differently, the frequency of "different" responses increased with increasing distance between patterns. Furthermore, when patterns were separated by $10.62 \mathrm{~mm}$, the subjects responded "different" most of the time. The increase in "different" responses and the decline in accuracy with increasing distance between patterns indicate that the

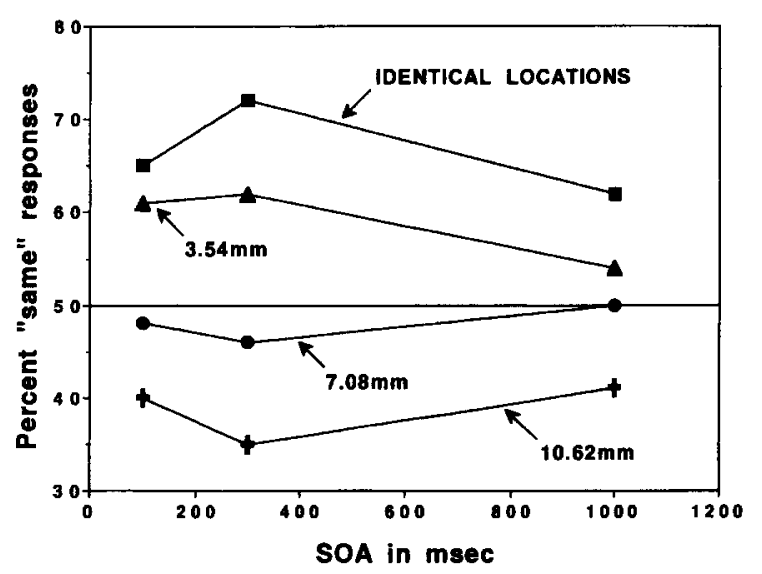

Figure 3. The percentage of "same" responses as a function of SOA when patterns were presented to ILs, or to NILs separated by 3.54 , 7.08 , or $10.62 \mathrm{~mm}$.

subjects responded "different" incorrectly on same trials when patterns were presented to NILs. That is, same patterns presented to NILs often felt like different patterns. Indeed, the subjects reported that a pair of " $T$ " patterns (or a pair of "L" patterns) felt different from each other when they occupied NILs. However, despite the preponderance of "same" responses when patterns occupied ILs, discrimination accuracy was higher in such situations than it was when patterns occupied NILs.

The RT data also supported the conclusion that same patterns at NILs often felt like different shapes. Table 1 shows mean RTs and mean percent correct on same and different trials for each location condition and for each SOA. A three-way repeated measures ANOVA on the accuracy data revealed an effect of SOA $[F(2,10)=27.58$, $p<.001]$ and an effect of location $[F(3,15)=5.8, p<.01]$, but no effect of trial type [same vs. different: $F(1,5)=$ $4.35, p>.05]$. A similar ANOVA on the RT data indicated that the only significant main effect was that of SOA $[F(2,10)=20.67, p<.001]$. Although the RT data showed no significant interaction between location and trial type, when patterns were at ILs, "same" responses were faster than "different" responses. This "fast-same effect" is similar to those found previously in tactile and visual studies of pattern discrimination (tactile: Evans \& Craig, 1991; Evans et al., 1992; visual: Bamber, 1969; Keuss, 1977; Krueger, 1973b; Nickerson, 1965; Pachella \& Miller, 1976). However, as the distance between patterns was increased, the fast-same effect not only disappeared, it in fact reversed. "Different" responses were faster than "same" responses when patterns were separated by $10.62 \mathrm{~mm}$. This reversal in RT is consistent with the observation that same patterns often felt like different shapes when they were at NILs.

One speculative explanation for the reduction in accuracy for patterns at NILs compared with those at ILs is that NILs on the fingerpad may have had different densities of innervation - the tips of the fingers, for example, may be more densely innervated than the area 
Table 1

Mean Percent Correct and Mean RT on Same and

Different Trials, for Each Location Condition and SOA*

\begin{tabular}{|c|c|c|c|c|c|c|c|c|}
\hline \multirow{3}{*}{$\begin{array}{l}\text { Location } \\
\text { Condition }\end{array}$} & \multicolumn{8}{|c|}{ Trials } \\
\hline & \multicolumn{4}{|c|}{ Same } & \multicolumn{4}{|c|}{ Different } \\
\hline & Correct $(\%)$ & $S E$ & $\mathrm{RT}(\mathrm{msec})$ & $S E$ & Correct $(\%)$ & $S E$ & RT (msec) & $S E$ \\
\hline \multicolumn{9}{|c|}{$100-\mathrm{msec} \mathrm{SOA}$} \\
\hline IL & 81.2 & 5.9 & 585 & 33 & 53.6 & 5.0 & 666 & 67 \\
\hline \multicolumn{9}{|l|}{ NIL: } \\
\hline $3.54 \mathrm{~mm}$ & 74.6 & 5.9 & 606 & 32 & 54.0 & 3.8 & 672 & 46 \\
\hline $7.08 \mathrm{~mm}$ & 56.3 & 5.6 & 658 & 36 & 59.7 & 4.5 & 676 & 31 \\
\hline $10.62 \mathrm{~mm}$ & 43.6 & 3.9 & 707 & 68 & 66.0 & 7.1 & 665 & 45 \\
\hline \multicolumn{9}{|c|}{$300-\mathrm{msec} \mathrm{SOA}$} \\
\hline IL & 93.3 & 3.5 & 517 & 32 & 51.0 & 6.9 & 693 & 46 \\
\hline \multicolumn{9}{|l|}{ NIL: } \\
\hline $3.54 \mathrm{~mm}$ & 83.3 & 4.2 & 557 & 36 & 56.6 & 7.0 & 671 & 48 \\
\hline $7.08 \mathrm{~mm}$ & 57.7 & 6.5 & 625 & 48 & 67.9 & 5.5 & 649 & 34 \\
\hline $10.62 \mathrm{~mm}$ & 46.7 & 5.5 & 690 & 62 & 76.9 & 4.7 & 630 & 36 \\
\hline \multicolumn{9}{|c|}{1,000 -msec SOA } \\
\hline IL & 94.1 & 2.2 & 618 & 35 & 68.7 & 5.5 & 694 & 36 \\
\hline \multicolumn{9}{|l|}{ NIL: } \\
\hline $3.54 \mathrm{~mm}$ & 84.7 & 2.6 & 644 & 30 & 76.0 & 6.1 & 673 & 40 \\
\hline $7.08 \mathrm{~mm}$ & 75.7 & 5.9 & 696 & 34 & 74.3 & 5.4 & 688 & 32 \\
\hline $10.62 \mathrm{~mm}$ & 58.7 & 6.2 & 761 & 29 & 78.0 & 6.9 & 678 & 32 \\
\hline
\end{tabular}

*Standard errors of means ( $S E$ ) are also shown.

lower down on the fingerpad (Johansson \& Vallbo, 1979; Vallbo \& Johansson, 1984) - and less densely innervated locations might filter more high-spatial-frequency information from patterns, thereby reducing pattern clarity. Discrimination performance might have been reduced if one member of a pair of patterns had some highspatial-frequency information removed and the other member did not, and thus performance might have deteriorated if patterns had been presented to locations with different innervation densities. The spatial resolution of Optacon patterns may be accomplished primarily by rapidly adapting mechanoreceptors (Gardner \& Palmer, 1989; Palmer \& Gardner, 1990), and these receptors may have a reduced innervation density lower on the fingerpad (Johansson \& Vallbo, 1979). The above explanation could also help to account for the increase in "different" responses when patterns were separated by $10.62 \mathrm{~mm}$. Krueger (1973a) found an analogous result in a visualdiscrimination task: Compared with the effect of symmetric irrelevant material or no material, asymmetric irrelevant material next to same pairs increased "different" responses, presumably because subjects were unable to completely filter out the irrelevant material. Thus, a match became a perceived mismatch on some trials. This issue will be addressed further in Experiment 2.

The results of the first experiment show that presenting patterns to NILs can affect processing of shape information, and suggest that location and shape information may be encoded together, at least for spatial patterns presented over the limited extent of the left index fingerpad. How generalizable are these results? Evans et al. (1992) trained subjects to respond to target patterns and found that similar stimuli presented simultaneously to a separate finger interfered with responses, even though the subjects were instructed to attend only to the targets. Evans et al. suggested that for stimuli presented to separate fingerpads, location information may not be intrinsically encoded with the identity of a pattern. Experiment 2 examined the effect of location when patterns were presented to separate fingerpads by repeating the procedure of Experiment 1, but this time presenting patterns to separate fingerpads instead of to a single fingerpad. It also explored whether or not innervation density plays a role in the effect of location on discrimination.

\section{EXPERIMENT 2}

What is the effect of location on discrimination when the physical distance between patterns is even greater than the distances in Experiment 1? Since accuracy in Figure 2 is not at chance level, performance might continue to decline as the distance between patterns is increased further. The greatest distance between locations that could be achieved on the same fingerpad was $10.62 \mathrm{~mm}$. One way to increase the distance between patterns is to present patterns to separate fingers- either adjacent fingers on the same hand, or fingers on opposite hands. The prediction is that accuracy would be lower for patterns on separate fingers than it would be for patterns at ILs. Should accuracy for patterns on separate fingers be reduced in comparison with accuracy for patterns at NILs on a single fingerpad, though? One view is that accuracy should suffer when patterns are on separate fingers because they are farther apart than patterns at NILs on a single fingerpad. An alternative view is that patterns at NILs on a single fingerpad stimulate adjacent 
areas of skin, some of which partially overlap, whereas patterns on separate fingers would stimulate discrete areas of skin, and that stimulating discrete areas rather than adjacent or overlapping areas should eliminate any spatial interactions that might tend to lower performance. It is thus difficult to make exact predictions concerning the level of discrimination accuracy when patterns are presented to separate fingers.

For patterns on separate fingers, the distance between patterns-essentially the distance between the fingersis similar, whether patterns are presented to corresponding points, such as the tops of both fingerpads, or to noncorresponding points, such as the top of one fingerpad and the bottom of the other. Therefore, one prediction is that changing where patterns are presented on separate fingerpads will have little effect on discrimination performance. However, there is some evidence to suggest that patterns presented to corresponding points may be processed in a unique manner during discrimination, although the exact nature of such processing is unclear (Gilson, 1968). Furthermore, when localizing a stimulus presented to one of several sites on the fingers of a single hand, subjects occasionally err and respond with a corresponding point on an adjacent finger (Elithorn, Piercy, \& Crosskey, 1952, 1953). Experiment 2 investigated whether corresponding points have any advantage over noncorresponding points when the shapes of spatial patterns are being processed.

It was noted in Experiment 1 that the reduction in accuracy on NIL trials in comparison with that on IL trials may have occurred because NILs differed in density of innervation. One way to test this possibility is to compare performance when patterns are at corresponding points on separate fingers with that when they are at noncorresponding points on separate fingers. Corresponding points on separate fingers should have similar densities of innervation, whereas noncorresponding points on separate fingers should have different innervation densities (Vallbo \& Johansson, 1984). Any reduction in performance for patterns at noncorresponding points compared with that at corresponding points could be due to different densities of innervation.

\section{Method}

Subjects. After participating in Experiment 1, the same six subjects participated in Experiment 2. One of the male undergraduates performed at chance level in Experiment 2, and his data were therefore excluded from the analysis.

Apparatus. The apparatus was the same as that used in Experiment 1 , except that two vibratory arrays were used instead of a single array.

Stimuli. The stimuli were the same as in Experiment 1. However, because some subjects had greater curvature at the ends of their fingers, only Locations 2 and 4, generated on the separate arrays, were used, to ensure that the entire extent of each pattern would be felt at each location.

Procedure. The same procedure was used as in Experiment 1, except for the following changes: the subjects placed one finger on each tactile array; for unilateral presentation, the subjects placed their left middle and left index fingerpads on the arrays and responded on the computer keyboard with their right hand; for bilat- eral presentation, the subjects placed their left middle and right index fingerpads on the arrays and responded using foot pedals that were also interfaced with the computer. The center-to-center distance between arrays was $4.5 \mathrm{~cm}$ (unilateral) or $8.4 \mathrm{~cm}$ (bilateral). On each trial, the subjects received the cue stimulus on each array simultaneously, and $1 \mathrm{sec}$ later, a pair of patterns were presented, one to each fingerpad, at the same SOAs as in Experiment 1 . The first pattern was always presented to the left middle finger. Subjects were asked to respond as accurately as possible, taking as much time as necessary; RT was not measured. Each subject participated in 10 sessions, with unilateral and bilateral presentations tested in alternate sessions. Within an experimental session, same and different trials were presented randomly in blocks of 50, each randomly presented block testing a different SOA. Each session contained 2 blocks per SOA condition, for a total of 6 blocks ( 300 trials). Because subjects had received practice by participating in Experiment 1, there were no practice sessions in Experiment 2.

\section{Results and Discussion}

The results were analyzed according to the locations of the two patterns on each trial, as in Experiment 1. The results averaged across subjects are shown in Figure 4, which shows $P(C)$ max as a function of SOA for unilateral and bilateral presentations; it also shows performance when both patterns were presented to Location 2 on separate fingers ( $\mathrm{L} 2,2)$, when both patterns were presented to Location 4 on separate fingers $(L 4,4)$, and when one pattern was presented to Location 2 on one finger and the other pattern to Location 4 on the other finger $(L 2,4)$ (i.e., the term " $L 2,4$ " refers to noncorresponding points on separate fingers, and the terms " $\mathrm{L} 2,2$ " and "L4,4" refer to corresponding points on separate fingers). Each data point on the $\mathrm{L} 2,2$ and $L 4,4$ functions represents, on average, 759 trials from five subjects, while each data point on the $\mathrm{L} 2,4$ functions represents, on average, 1,482 trials from five subjects. The standard errors of the means ranged from $2 \%$ to $7 \%$ and did not differ systematically across locations, SOAs, or presentation type. The data for three of the five subjects were similar to those shown in Figure 4, while that for the remaining two subjects showed a closer overlap of the three functions ( $\mathrm{L} 2,2, \mathrm{~L} 4,4$, and $\mathrm{L} 2,4)$.

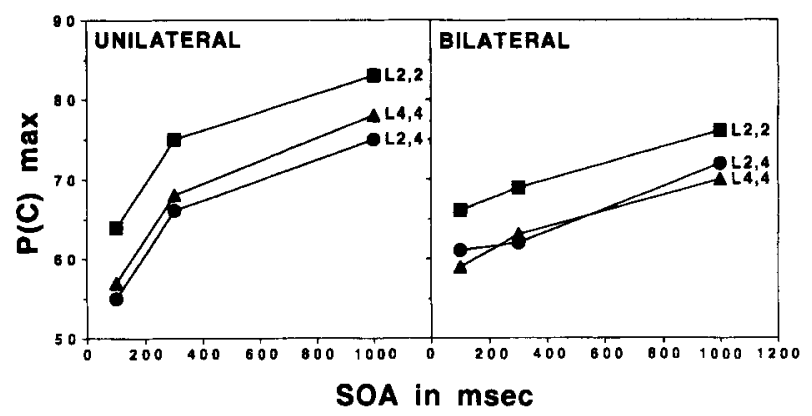

Figure 4. Discrimination accuracy $[\mathrm{P}(\mathrm{C})$ max $]$ plotted as a function of SOA for unilateral and bilateral presentation. $L 2,2=$ data when patterns were at $L$ ocation 2 on separate fingers; $L A, 4=$ data when patterns were at Location 4 on separate fingers; $L, 2,4=$ data when patterns were at Location 2 and Location 4 on separate fingers. 
The results of a three-way repeated measures ANOVA on the L2,2 and L4,4 data in Figure 4 revealed no significant effect of location $[F(1,4)=1.81, p>.05]$. However, there was an effect of SOA $[F(2,8)=94.50, p<$ $.001]$, showing that, as in Experiment 1, discrimination performance improved with increasing SOA. There was no effect of unilateral versus bilateral presentation $[F(1,4)$ $=1.68, p>.05]$, indicating that overall performance was similar, whether patterns were presented to fingers on the same hand or to fingers on different hands. Although Craig (1985a) and Horner (1992) found that bilateral performance was higher than unilateral performance for SOAs up to $100 \mathrm{msec}$, the bilateral advantage disappeared, or was greatly reduced, at longer SOAs, presumably because the subjects had more time to attend to both fingers, whether they were on the same hand or on different hands. Figure 4 also shows a small bilateral advantage at the $100-\mathrm{msec}$ SOA, and a small unilateral advantage at the longer SOAs. The fact that only SOAs of $100 \mathrm{msec}$ or longer were used in the present study may explain the absence of a bilateral advantage: At SOAs longer than $100 \mathrm{msec}$, the subjects may have had an increased ability to switch attention from one finger to another, thus reducing the bilateral advantage (Craig, 1985a). There were no significant interactions $(p>.05)$.

A comparison of the data in Figures 2 and 4 shows that presenting patterns to separate fingers reduced accuracy compared with accuracy at ILs, a result that was significant for both unilateral presentation $[F(1,4)=34.73$, $p<.01]$ and bilateral presentation $[F(1,4)=82.37, p<$ $.01]$. The statistical comparisons excluded from Experiment 1 the data from the subject who performed at chance level in Experiment 2, as well as the data from all subjects for Locations 1 and 3 in Experiment 1. Performance for separate fingers was lower than that for ILs, despite the fact that the subjects were instructed only to be concerned with accuracy in Experiment 2, whereas in Experiment 1 , they received both speed and accuracy instructions. Such a result extends the findings of Experiment 1 and generalizes the effect of varying pattern location to locations on separate fingers. Thus, discrimination is poor when patterns are presented to separate fingers or to NILs on a single finger, and improves when patterns occupy ILs.

Increasing the maximum separation between locations from $10.62 \mathrm{~mm}$ in Experiment 1 to $4.5 \mathrm{~cm}$ (unilateral) or $8.4 \mathrm{~cm}$ (bilateral) in Experiment 2 did not reduce accuracy much, suggesting that the limiting factor in discriminating patterns may not simply be the physical distance between them. Craig (1985a) found that varying the physical distance between patterns on different hands had little effect on the ability to divide attention between the patterns or combine the patterns. Furthermore, the distance between fingers on different hands is usually greater than the distance between adjacent fingers on the same hand, and yet these distances played little role in discriminability in the present study, as indicated by the lack of a significant unilateral-bilateral difference. Recent evidence suggests that adjacent fingers on one hand may be perceptually as distant as nonadjacent fingers on the same hand (Evans et al., 1992). The relative physical locations of haptically explored objects may also contribute to perceptual distance. In short, the relationship between physical distance and perceptual distance is unclear at present.

The potential role of differences in innervation density at separate locations was examined by comparing performance at corresponding points, where the densities of innervation should be similar, with performance at noncorresponding points, where the densities of innervation may differ. The data from the L2,2 and L4,4 functions in Figure 4 were pooled and compared with the L2,4 functions, using a three-way repeated measures ANOVA. The result of this analysis showed a significant difference between the pooled L2,2 and L4,4 data and the L2,4 data $[F(1,4)=24.38, p<.01]$, indicating an advantage for processing patterns at corresponding points in comparison with noncorresponding points. Therefore, differences in innervation density may be responsible for reducing discrimination performance when patterns are presented to noncorresponding points on separate fingers, compared with that when patterns are presented to corresponding points. Furthermore, the results suggest that differences in innervation density may also have contributed to the reduction in accuracy when patterns were presented to NILs on a single finger in Experiment 1.

In Experiment 1, the tendency to respond "same" declined as the distance between patterns increased. If the decline in "same" responses occurred only because patterns occupied separate locations, one would expect a similar decline in "same" responses when patterns occupied corresponding points on separate fingers. Alternatively, the change in "same" responses in Experiment 1 could have been due to presenting patterns to locations with different densities of innervation. If so, one would expect little change in "same" responses when patterns were presented to corresponding points on separate fingers compared with when they were presented to ILs, because in both cases patterns occupied locations with similar innervation densities. Rates of responding "same" averaged across SOA are shown in Table 2 for unilateral and bilateral presentations.

A comparison of these rates with those in Figure 3 shows that, compared with those for patterns at ILs, "same" responses were reduced when patterns occupied corresponding points on separate fingers, indicating that preventing patterns from occupying ILs does reduce the tendency to respond "same." However, the size of the re-

Table 2

Mean Percent "Same" Responses $(M)$ Averaged Across SOA and Standard Error ( $S E$ ), for Each Location and Type of Presentation

\begin{tabular}{|c|c|c|c|c|}
\hline \multirow{3}{*}{$\begin{array}{c}\text { Location } \\
\text { Condition }\end{array}$} & \multicolumn{4}{|c|}{ Presentation } \\
\hline & \multicolumn{2}{|c|}{ Unilateral } & \multicolumn{2}{|c|}{ Bilateral } \\
\hline & $M(\%)$ & $S E$ & $M(\%)$ & $S E$ \\
\hline $\mathrm{L} 2,2$ & 60.3 & 3.7 & 55.5 & 3.5 \\
\hline $\mathrm{L} 4,4$ & 63.5 & 4.0 & 59.4 & 2.6 \\
\hline $\mathrm{L} 2,4$ & 51.8 & 2.4 & 48.3 & 2.0 \\
\hline
\end{tabular}


duction in "same" responses for patterns at corresponding points on separate fingers was small compared with the size of the reduction in "same" responses for patterns at NILs on a single finger, suggesting that innervation density may also have contributed to the reduction in "same" responses for patterns at NILs. In addition, the percentage of "same" responses was higher for patterns at corresponding points than it was for those at noncorresponding points, for both unilateral presentation $[F(1,4)=$ $26.66, p<.01]$ and bilateral presentation $[F(1,4)=25.66$, $p<.01]$, suggesting that differences in innervation density may have had an influence.

The left middle and index fingers were used for unilateral presentation. However, index fingers may be slightly more sensitive than middle fingers (Foulke, 1964; Lappin \& Foulke, 1973; Lederman, 1976; Weinstein, 1968). Because of this difference in sensitivity, rather than using matching bilateral fingers (both index or both middle fingers), the left middle and right index fingers were used for bilateral presentation, to provide a more direct comparison with unilateral performance. Had matching bilateral fingers been used, one would have predicted, a priori, an advantage (if both index fingers were used) or a disadvantage (if both middle fingers were used) compared with unilateral presentation. One potential disadvantage of the fact that the pairs of fingers used in Experiment 2 were nonmatching is that innervation densities at corresponding points for middle and index fingers may vary somewhat - a fact that makes the difference in performance between corresponding and noncorresponding points even more compelling. If both middle fingers or both index fingers were used for bilateral presentation, the difference in performance between corresponding and noncorresponding points should be the same as it was in Experiment 2, or perhaps greater.

Additional measurements were taken to explore this possibility. Specifically, the procedure of Experiment 2 was repeated, using only the 1,000-msec SOA condition, but with all possible pairwise combinations of the middle fingers and index fingers of the left and right hands tested in separate blocks within each session. The subjects used foot pedals to respond in all six conditions. In addition, the set of patterns shown in Figure 5 was used to ensure the generality of the results, and the pattern duration was increased from $26 \mathrm{msec}$ to $100 \mathrm{msec}$. Six new experienced undergraduate subjects (four females and two a)

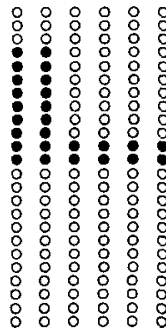

LOCATION 2

\section{b) LOCATION 4}
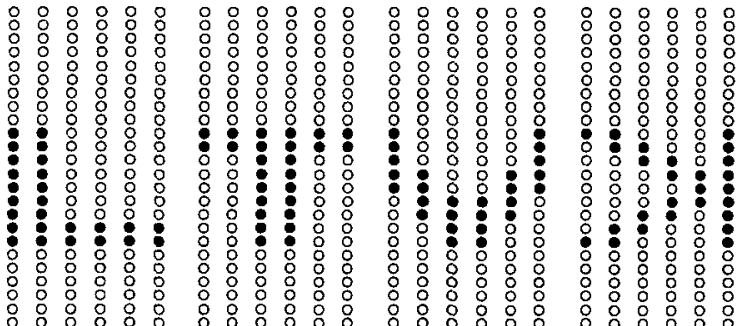

Figure 5. Representations of the patterns used in the additional measurements following Experiment 2. (a) and (b) represent the two array locations at which the pattems were presented. Filled circles indicate activated pins in the array; unfilled circles indicate inactive pins.

males) participated in six sessions each (50 trials per condition in each session). The results are shown in Table 3.

The L2,2 and L4,4 data in Table 3 were pooled and compared with the $\mathrm{L} 2,4$ data, revealing a significant difference $[F(1,5)=15.70, p<.02]$. Thus, the difference in performance between corresponding and noncorresponding points was replicated using the additional finger pairings and a larger set of patterns. There was no significant effect of finger pair $[F(5,25)=2.45, p>.05]$, suggesting that there was no difference between unilateral and bilateral presentation in terms of performance, as was true for the 1,000-msec SOA in Experiment 2 . However, a paired $t$ test using the pooled L2,2 and L4,4 data did show a significant difference between the two types of unilateral presentations (i.e., those involving the middle and index fingers of the left hand, and those in-

Table 3

P(C) Max (PCM) Averaged Across Subjects, ${ }^{*}$ for Each Location and Presentation Condition

\begin{tabular}{|c|c|c|c|c|c|c|c|c|c|c|c|c|}
\hline \multirow{4}{*}{$\begin{array}{l}\text { Location } \\
\text { Condition }\end{array}$} & \multicolumn{12}{|c|}{ Presentation } \\
\hline & \multicolumn{4}{|c|}{ Unilateral } & \multicolumn{8}{|c|}{ Bilateral } \\
\hline & \multicolumn{2}{|c|}{ LM-LI } & \multicolumn{2}{|c|}{ RM-RI } & \multicolumn{2}{|c|}{ LM-RI } & \multicolumn{2}{|c|}{ LM-RM } & \multicolumn{2}{|c|}{ LI-RI } & \multicolumn{2}{|c|}{ LI-RM } \\
\hline & PCM & $S E$ & PCM & $S E$ & $\mathrm{PCM}$ & $S E$ & $\mathrm{PCM}$ & $\overline{S E}$ & PCM & $S E$ & PCM & $S E$ \\
\hline $\mathrm{L} 2,2$ & 69.1 & 3.7 & 56.6 & 3.1 & 72.6 & 5.3 & 66.6 & 2.7 & 70.1 & 2.9 & 65.6 & \\
\hline $\mathrm{L} 4,4$ & 66.2 & 3.6 & 53.5 & 2.5 & 59.8 & 2.6 & 61.4 & 2.9 & 54.1 & 3.8 & 63.4 & \\
\hline L2,4 & 69.0 & 6.9 & 56.4 & 1.8 & 61.2 & 2.7 & 59.7 & 3.4 & 59.2 & 2.7 & 60.1 & 4.0 \\
\hline
\end{tabular}

Note*-Standard error $(S E)$ is also shown for each location and presentation condition. $\mathrm{LM}=$ left middle finger; $\mathrm{LI}=$ left index finger; $\mathrm{RM}=$ right middle finger; $\mathrm{RI}=$ right index finger. 
volving the middle and index fingers of the right hand $[t(5)=4.83, p<.01]$. The subjects use their left hands more often than their right hands when testing in the laboratory, and the observed difference between hands may be due to experience (Craig, 1988). It could also be due to a left-hand advantage in perception of tactile patterns (Heller, Rogers, \& Perry, 1990; Hermelin \& O'Connor, 1971; Mommers, 1980).

\section{GENERAL DISCUSSION}

The present study produced four main findings: (1) Increasing the distance between patterns on a single fingerpad reduced discrimination accuracy and increased RT; (2) the effect of location was independent of the time between successive patterns; (3) same patterns presented to separate locations on a single fingerpad often felt like different patterns; and (4) compared with that at ILs, accuracy declined when patterns were presented to separte fingers, but there was an advantage for processing patterns at corresponding points over processing them at noncorresponding points. The fact that location affects discrimination suggests that location and shape are important features of spatial patterns, and this is consistent with the subjects' reports that patterns felt different when presented to NILs on a single finger.

If the spatial relationships of patterns on a single finger are preserved, and shape and location are important features of patterns, comparing patterns at ILs should be easier and quicker than comparing patterns at NILs. Discriminating between patterns at ILs would involve only comparing their shapes, whereas discriminating between patterns at NILs would require comparing shapes and taking into account pattern locations. The data are consistent with theories in which distinguishing between a pair of patterns is accomplished by comparing the amount of overlap between representations of the patterns (Bamber, 1969; Krueger, 1978; Neisser, 1967). Patterns may be represented, at least functionally, as templates that must be brought into registry with one another for comparison (Bamber, 1969; Neisser, 1967; Silverman, 1973). Representations of patterns at ILs would already be in registry and would require no alignment. However, representations of patterns at NILs, whether on a single finger or on separate fingers, would require some alignment. The alignment of pattern representations might result in a reduction in accuracy with increasing distance between patterns. According to this view, the separation between RT functions in Figure 2 may represent the time taken to bring templates of each pattern into alignment for comparison. The fact that the RT functions are parallel is consistent with the notion that alignment time depends primarily on the distance between patterns.

One speculation is that differences in density of innervation among pattern locations may also have affected discrimination performance. If the tip of the fingerpad has a greater density of innervation than the bottom of the fingerpad, presenting the same pattern to NILs on a single fingerpad would result in the pattern feeling dif- ferent at one location than at another. Presumably, locations with lower densities of innervation would filter more high-spatial-frequency information than would locations with higher densities of innervation. As long as both patterns in a pair are presented to ILs, discrimination performance would not suffer much; however, when a pair of patterns are presented to NILs, more high-frequency information would be filtered from one of the patterns than from the other pattern, resulting in a decline in discriminability. This explanation would also account for the difference in performance between patterns at corresponding points and at noncorresponding points on separate fingers.

The following findings from previous studies support the above explanation: First, compared with that at the tip of the fingerpad, two-point discriminability is reduced at the bottom of the fingerpad (proximal to the whorl of the papillary ridges; Vallbo \& Johansson, 1978), and this reduction matches the decline in the density of innervation (Johansson \& Vallbo, 1983); second, the change in innervation density from the tip to the bottom of the fingerpad is sudden rather than gradual ( $\mathrm{J}_{\mathrm{O}}-$ hansson \& Vallbo, 1983); and finally, Optacon reading rates are drastically slower when the bottom of the fingerpad is used than they are when the top of the fingerpad is used (Hill, 1974). Loomis (1981a, 1981b) has suggested that tactile letter recognition is determined primarily by the low-spatial-frequency content of patterns, and it would have been interesting to see if the same discrimination effects held for larger patterns than were used in the current study. The spectral content of larger patterns would be better accommodated by the low-pass spatialfiltering characteristics of the skin, and one would predict a reduced effect of varying location. Unfortunately, both array size and the size of the fingerpad limited the sizes of the patterns used in the present study.

Despite the fact that location is preserved in the primary somatosensory cortex, the present results suggest that the effect of location on shape discrimination cannot be explained simply in terms of the distance separating cortical representations of patterns. The distance separating cortical areas that process information from NILs on a single finger should be similar to the distance separating areas that process corresponding points on adjacent fingers. As expected, these conditions led to reduced discrimination performance in comparison with the condition in which single areas of cortex processed information from ILs on the fingerpad. The findings for bilateral presentations, however, were not as expected. The cortical projection areas for stimuli presented bilaterally are in separate hemispheres, and the cortical distance separating these areas is therefore greater than the distance separating areas that represent corresponding points on adjacent fingers - yet there was no reduction in performance for bilateral discrimination, in comparison with performance for unilateral discrimination. Rather than relying on an anatomical frame of reference when distinguishing between patterns, subjects may rely on an external frame of reference, as has been suggested 
in studies of tactile localization (Elithorn et al., 1952, 1953). In addition, Rinker and Craig (1994) found that externally defined directions of motion on a nontarget finger interfered with subjects' responses to motion on the target finger, even when the subjects were explicitly told to ignore the nontarget finger. This tactile external frame of reference may be roughly analogous to a visualobject-centered coordinate frame (Marr, 1982).

The results have implications for the improvement of tactile communication systems, such as braille and the Optacon, that rely on the ability to process successive spatial patterns. Much has been written about the temporal and spatial limitations imposed by presenting patterns successively to a single location on the skin (Craig, 1976, 1978, 1983a, 1983b, 1985b). Temporal interactions might be avoided by reducing the rate at which patterns are presented to the skin, but this would be at the risk of also reducing the rate of information processing (Craig $\&$ Sherrick, 1982; but see also Kirman, 1973). Indeed, the IL results in Figure 2 show that discrimination accuracy improves when there is more time between patterns. Spatial interactions might be avoided by presenting patterns to separate fingers, but this might cause performance to be limited by attentional constraints (Craig, 1985a), and the present results indicate that there may be a spatial limitation on perception as well, in that the ability to discriminate shapes would be reduced, since the patterns are not at ILs. The present results also indicate that presenting successive spatial patterns to NILs on the same finger is unlikely to improve discrimination accuracy. Presenting patterns to other body sites than the fingers might provide a way of avoiding these limitations on processing, and it might be informative to compare the effect of varying pattern location on the fingers, as done here, with the effect of varying location at other sites.

\section{REFERENCES}

Allard, T., \& Merzenich, M. M. (1988). Some basic organizational features of the somatosensory nervous system. In W. Von Seelen, G. Shaw, \& U. M. Leinhos (Eds.), Organization of neural networks: Structures and models (pp. 267-284). Weinheim, Germany: VCH.

BAMBER, D. (1969). Reaction times and error rates for "same-different" judgments of multidimensional stimuli. Perception \& Psychophysics, 6, 169-174.

Bliss, J. C., Katcher, M. H., Rogers, C. H., \& Shepard, R. P. (1970). Optical-to-tactile image conversion for the blind. IEEE Transactions on Man-Machine Systems, 11, 58-64.

BLISS, J. C., \& LinviLL, J. G. (1966). A direct translation reading aid: Reading alphabetic shapes tactually. In R. Dufton (Ed.), Proceedings of the international conference on sensory devices for the blind (pp. 389-407). London: Arrowsmith.

Cholewiak, R. W., \& CRaig, J. C. (1984). Vibrotactile pattern recognition and discrimination at several body sites. Perception \& Psychophysics, 35, 503-514.

Craig, J. C. (1976). Vibrotactile letter recognition: The effect of a masking stimulus. Perception \& Psychophysics, 20, 317-326.

Craig, J. C. (1977). Vibrotactile pattern perception: Extraordinary observers. Science, 196, 450-452.

Craig, J. C. (1978). Vibrotactile pattern recognition and masking. In $\mathrm{G}$. Gordon (Ed.), Active touch - the mechanism of recognition of objects by manipulation: A multi-disciplinary approach (pp. 229-242). Oxford: Pergamon.
Craig, J. C. (1980). Modes of vibrotactile pattern perception. Journal of Experimental Psychology: Human Perception \& Performance, 6 , 151-166.

CraIG, J. C. (1982a). Temporal integration of vibrotactile patterns. Perception \& Psychophysics, 32, 219-229.

CRAIG, J. C. (1982b). Vibrotactile masking: A comparison of energy and pattern maskers. Perception \& Psychophysics, 31, 523-529.

CRAIG, J. C. (1983a). The role of onset in the perception of sequentially presented vibrotactile patterns. Perception \& Psychophysics, 34, 421-432.

Craig, J. C. (1983b). Some factors affecting tactile pattern recognition. International Journal of Neuroscience, 19, 47-58.

CRAIG, J. C. (1985a). Attending to two fingers: Two hands are better than one. Perception \& Psychophysics, 38, 496-511.

CRAIG, J. C. (1985b). Tactile pattern perception and its perturbations. Journal of the Acoustical Society of America, 77, 238-246.

CRAIG, J. C. (1988). The role of experience in tactual pattern perception: A preliminary report. International Journal of Rehabilitation Research, 11, 167-171.

CraIG, J. C. (1989). Interference in localizing tactile stimuli. Perception \& Psychophysics, 45, 343-355.

Craig, J. C., \& Evans, P. M. (1987). Vibrotactile masking and the persistence of tactual features. Perception \& Psychophysics, 42, 309-317.

Craig, J. C., \& SHerrick, C. E. (1982). Dynamic tactile displays. In W. Schiff \& E. Foulke (Eds.), Tactual perception: A sourcebook (pp. 209-233). Cambridge: Cambridge University Press.

Elithorn, A., Piercy, M. F., \& Crosskey, M. A. (1952). Some mechanisms of tactile localization revealed by a study of leucotomized patients. Journal of Neurology, Neurosurgery, \& Psychiatry, 15, 272-282.

Elithorn, A., Piercy, M. F., \& Crosskey, M. A. (1953). Tactile localization. Quarterly Journal of Experimental Psychology, 5, 171-182.

Estes, W. K., Allmeyer, D. H., \& Reder, S. M. (1976). Serial position functions for letter identification at brief and extended exposure durations. Perception \& Psychophysics, 19, 1-15.

Evans, P. M. (1987). Vibrotactile masking: Temporal integration, persistence, and strengths of representations. Perception \& Psychophysics, 42, 515-525.

Evans, P. M., \& Craig, J. C. (1986). Temporal integration and vibrotactile backward masking. Journal of Experimental Psychology: Human Perception \& Performance, 12, 160-168.

Evans, P. M., \& CRAIG, J. C. (1991). Tactile attention and the perception of moving tactile stimuli. Perception \& Psychophysics, 49, 355-364.

Evans, P. M., Craig, J. C., \& Rinker, M. A. (1992). Perceptual processing of adjacent and nonadjacent tactile nontargets. Perception \& Psychophysics, 52, 571-581.

FoULKE, E. (1964). Transfer of a complex perceptual skill. Perceptual \& Motor Skills, 18, 733-740.

Gardner, E. P., \& PAlmer, C. I. (1989). Simulation of motion on the skin: I. Receptive fields and temporal frequency coding by cutaneous mechanoreceptors of Optacon pulses delivered to the hand. Journal of Neurophysiology, 62, 1410-1436.

GiLson, R. D. (1968). Some factors affecting the spatial discrimination of vibrotactile patterns. Perception \& Psychophysics, 3, 131-136.

Heller, M. A., Rogers, G. J., \& Perry, C. L. (1990). Tactile pattern recognition with the Optacon: Superior performance with active touch and the left hand. Neuropsychologia, 28, 1003-1006.

HeRmelin, B., \& O'CONNOR, N. (1971). Functional asymmetry in the reading of Braille. Neuropsychologia, 9, 431-435.

HiLL, J. W. (1974). Limited field of view in reading lettershapes with the fingers. In F. A. Geldard (Ed.), Cutaneous communication systems and devices (pp. 95-105). Austin, TX: Psychonomic Society.

HORNER, D. T. (1991). The effects of complexity on the perception of vibrotactile patterns. Perception \& Psychophysics, 49, 551-562.

HORNER, D. T. (1992). The effects of complexity on the perception of vibrotactile patterns presented to separate fingers. Perception \& Psychophysics, 52, 201-210.

Horner, D. T., \& Craig, J. C. (1989). A comparison of discrimination and identification of vibrotactile patterns. Perception \& Psychophysics, 45, 21-30.

Johansson, R. S., \& VAllbo, A. B. (1979). Tactile sensibility in the 
human hand: Relative and absolute densities of the four types of mechanoreceptive units in glabrous skin. Journal of Physiology, 286, 283-300.

Johansson, R. S., \& VAlLBo, A. B. (1983). Tactile sensory coding in the glabrous skin of the human hand. Trends in Neuroscience, 6, 27-32.

KaAs, J. H., Merzenich, M. M., \& Killackey, H. P. (1984). The reorganization of somatosensory cortex following peripheral nerve damage in adult and developing mammals. Annual Review of Neuroscience, 6, 325-356.

Keuss, P. J. G. (1977). Processing of geometrical dimensions in a binary classification task: Evidence for a dual process model. Perception \& Psychophysics, 21, 371-376.

KiRman, J. H. (1973). Tactile communication of speech: A review and an analysis. Psychological Bulletin, 80, 54-74.

KRUEGER, L. E. (1973a). Effect of irrelevant surrounding material on speed of same-different judgment of two adjacent letters. Journal of Experimental Psychology, 98, 252-259.

KRUEGER, L. E. (1973b). Effect of stimulus frequency on speed of same-different judgments. In S. Kornblum (Ed.), Attention and performance IV (pp. 497-506). New York: Academic Press.

KrUeger, L. E. (1978). A theory of perceptual matching. Psychological Review, 85, 278-304.

LAPPIN, J. S., \& FoulKE, E. (1973). Expanding the tactual field of view. Perception \& Psychophysics, 14, 237-241.

Lederman, S. J. (1976). The "callus-thenics" of touching. Canadian Journal of Psychology, 30, 82-89.

LoOMIS, J. M. (1980). Interaction of display mode and character size in vibrotactile letter recognition. Bulletin of the Psychonomic Society, 16, 385-387.

Loomis, J. M. (1981a). Tactile pattern perception. Perception, 10, 5-27.

Loomis, J. M. (1981b). On the tangibility of letters and braille. Perception \& Psychophysics, 29, 37-46.

Loomis, J. M., \& APKarian-STIELAd, P. (1976). A lateral masking effect in tactile and blurred visual letter recognition. Perception \& Psychophysics, 20, 221-226.

MARR, D. (1982). Vision: A computational investigation into the human representation and processing of visual information. San Francisco: W. H. Freeman.

Maunsell, J. H. R., \& Newsome, W. T. (1987). Visual processing in monkey extrastriate cortex. Annual Review of Neuroscience, 10 , 363-401

MCFADDEN, D. (1970). Three computational versions of proportion correct for use in forced-choice experiments. Perception \& Psychophysics, 8, 336-342.

Merzenich, M. M., KaAs, J. H., Wall, J. T., Nelson, R. J., Sur, M., \& FELLEMAN, D. (1983). Topographic reorganization of somatosensory cortical areas $3 \mathrm{~b}$ and 1 in adult monkeys following restricted deafferentation. Neuroscience, 8, 33-55.

Merzenich, M. M., Nelson, R. J., Stryker, M. P., Cynader, M. S., SCHOPPMANN, A., \& ZoOK, J. M. (1984). Somatosensory cortical map changes following digit amputation in adult monkeys. Journal of Comparative Neurology, 24, 591-605.

Mishkin, M., UNgerleider, L. G., \& Macko, K. A. (1983). Object vision and spatial vision: Two cortical pathways. Trends in Neurosciences, 6, 414-417.

Mommers, M. J. C. (1980). Braille reading: Effects of different hand and finger usage. Journal of Visual Impairment \& Blindness, 74, 338-343.

Mozer, M. C. (1989). Types and tokens in visual letter perception.
Journal of Experimental Psychology: Human Perception \& Performance, 15, 287-303.

NeIsser, U. (1967). Cognitive psychology. New York: Appleton-Century-Crofts.

NiCKERSON, R. S. (1965). Response times for same-different judgments. Perceptual \& Motor Skills, 20, 15-18.

Nolan, C. Y., \& Kederis, C. J. (1969). Perceptual factors in braille word recognition. New York: American Foundation for the Blind.

Pachella, R. G., \& Miller, J. O. (1976). Stimulus probability and same-different classification. Perception \& Psychophysics, 19, 29-34.

Palmer, C. I., \& Gardner, E. P. (1990). Simulation of motion on the skin: IV. Responses of Pacinian corpuscle afferents innervating the primate hand to stripe patterns on the OPTACON. Journal of Neurophysiology, 64, 236-247.

PosNer, M. I., \& Mitchell, R. F. (1967). Chronometric analysis of classification. Psychological Review, 74, 392-409.

Proctor, R. W. (1981). A unified theory for matching task phenomena. Psychological Review, 88, 291-326.

ReEd, C. M., Durlach, N. J., Braida, L. D., \& Schultz, M. C. (1982). Analytic study of the Tadoma method: Identification of consonants and vowels by an experienced Tadoma user. Journal of Speech \& Hearing Research, 25, 108-116.

RINKER, M. A., \& CraIG, J. C. (1994). The effect of spatial orientation on the perception of moving tactile stimuli. Perception \& Psychophysics, 56, 356-362.

Robinson, J. S., Brown, L. T., \& Hayes, W. H. (1964). Test of effects of past experience on perception. Perceptual \& Motor Skills, 18, 953-956.

SCADDEN, L. A. (1969). A tactual substitute for sight. New Scientist, 41, 677-678.

SCADDEN, L. A. (1973). Tactile pattern recognition and body loci. Perception, 2, 333-336.

Silverman, W. P. (1973). The perception of identity in simultaneously presented complex visual displays. Memory \& Cognition, 1, 459-466.

Treisman, A., \& Gelade, G. (1980). A feature integration theory of attention. Cognitive Psychology, 12, 97-136.

UNGERLEIDER, L. G., \& MISHKIN, M. (1982). Two cortical visual systems. In D. J. Ingle, M. A. Goodale, \& R. J. W. Mansfield (Eds.), Analysis of visual behavior (pp. 549-586). Cambridge, MA: MIT Press.

VaLlBo, A. B., \& Johansson, R. S. (1978). The tactile sensory innervation of the glabrous skin of the human hand. In G. Gordon (Ed.), Active touch - the mechanism of recognition of objects by manipulation: A multi-disciplinary approach (pp. 29-54). Oxford: Pergamon.

Vallbo, A. B., \& Johansson, R. S. (1984). Properties of cutaneous mechanoreceptors in the human hand related to touch sensation. Human Neurobiology, 3, 3-14.

WEINSTEIN, S. (1968). Intensive and extensive aspects of tactile sensitivity as a function of body part, sex, and laterality. In D. R. Kenshalo (Ed.), The skin senses (pp. 195-222). Springfield, IL: Charles C. Thomas.

WeISENBERgER, J. M. (1981). Tactile pattern similarity. Unpublished doctoral dissertation, Indiana University, Bloomington.

Weisenberger, J. M., \& Craig, J. C. (1982). A tactile metacontrast effect. Perception \& Psychophysics, 31, 530-536.

White, B. W., Saunders, F. A., Scadden, L., Bach-y-Rita, P., \& Collins, C. C. (1970). Seeing with the skin. Perception \& Psychophysics, 7, 23-27.

(Manuscript received September 29, 1993; revision accepted for publication October 26, 1994.) 